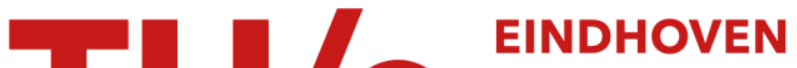

\section{A compact integrated polarization splitter/converter in InGaAsP/InP}

\section{Citation for published version (APA):}

Augustin, L. M., Hanfoug, R., Tol, van der, J. J. G. M., Laat, de, W. J. M., \& Smit, M. K. (2007). A compact integrated polarization splitter/converter in InGaAsP/InP. IEEE Photonics Technology Letters, 19(17), 12861288. https://doi.org/10.1109/LPT.2007.902277

DOI:

10.1109/LPT.2007.902277

Document status and date:

Published: 01/01/2007

\section{Document Version:}

Publisher's PDF, also known as Version of Record (includes final page, issue and volume numbers)

\section{Please check the document version of this publication:}

- A submitted manuscript is the version of the article upon submission and before peer-review. There can be important differences between the submitted version and the official published version of record. People interested in the research are advised to contact the author for the final version of the publication, or visit the $\mathrm{DOI}$ to the publisher's website.

- The final author version and the galley proof are versions of the publication after peer review.

- The final published version features the final layout of the paper including the volume, issue and page numbers.

Link to publication

\section{General rights}

Copyright and moral rights for the publications made accessible in the public portal are retained by the authors and/or other copyright owners and it is a condition of accessing publications that users recognise and abide by the legal requirements associated with these rights.

- Users may download and print one copy of any publication from the public portal for the purpose of private study or research.

- You may not further distribute the material or use it for any profit-making activity or commercial gain

- You may freely distribute the URL identifying the publication in the public portal.

If the publication is distributed under the terms of Article 25fa of the Dutch Copyright Act, indicated by the "Taverne" license above, please follow below link for the End User Agreement:

www.tue.nl/taverne

Take down policy

If you believe that this document breaches copyright please contact us at:

openaccess@tue.nl

providing details and we will investigate your claim. 


\title{
A Compact Integrated Polarization Splitter/Converter in InGaAsP-InP
}

\author{
L. M. Augustin, Student Member, IEEE, R. Hanfoug, J. J. G. M. van der Tol, W. J. M. de Laat, and \\ M. K. Smit, Fellow, IEEE
}

\begin{abstract}
A novel design for an integrated passive polarization splitter/converter combination is presented. The device consists of a Mach-Zehnder interferometer with polarization converters in both arms. The device is analyzed using the transfer matrix method and fabricated in InGaAsP-InP. Measurement results show a splitting ratio of approximately $10 \mathrm{~dB}$ and a conversion of $>90 \%$. This device can be monolithically integrated with passive and active components.
\end{abstract}

Index Terms-Indium phosphide, integrated devices, polarization converter (PC), polarization splitter, wafer stepper.

\section{INTRODUCTION}

$\mathbf{T}$ HE polarization state of light is of ever greater importance in modern telecommunications networks. First of all, a lot of components in the network are highly polarization-dependent; furthermore, polarization-mode dispersion can degrade the transmission in an optical fiber. On the other hand, the polarization can be employed in, e.g., polarization multiplexing, polarization diversity, and polarization-based filtering [1]. In all these cases, polarization splitters and converters are key elements.

Passive polarization splitters and converters that are able to be integrated with both active and passive components are preferred. Passive polarization splitting can be achieved by loading a waveguide with metal [2], by mode-evolution [3], [4], or by modal birefringence [5], [6]. Splitters based on the latter have the advantage that they have low loss and show a high splitting ratio. A drawback is their length $(1-3 \mathrm{~mm})$ which is large compared to other components on the chip. Shorter splitters based on photonic crystal waveguides [7] are reported, but these have the disadvantage of higher losses and more complex processing. We present a compact $600-\mu \mathrm{m}$-long integrated splitter based on polarization converters $(\mathrm{PCs})$; preliminary results were shown in [8].

\section{PRINCIPLE}

The device consists of a Mach-Zehnder interferometer (MZI) with PCs in both arms, as is depicted in Fig. 1. Light coupled into

Manuscript received February 16, 2007; revised May 3, 2007. This work was supported by the European Commission in the IST-MUFINS Project, and facilitated by ASML in Veldhoven, and by the NRC Photonics funded by the Netherlands Foundation for Scientific Research (NWO).

L. M. Augustin, J. J. G. M. van der Tol, and M. K. Smit are with the COBRA Research Institute, Eindhoven University of Technology, 5600 MB Eindhoven, The Netherlands (e-mail: 1.m.augustin@tue.nl).

R. Hanfoug is with MAPPER Lithography B.V., 2628 XK Delft, The Netherlands.

W. J. M. de Laat is with ASML, 5504 DR Veldhoven, The Netherlands.

Color versions of one or more of the figures in this letter are available online at http://ieeexplore.ieee.org.

Digital Object Identifier 10.1109/LPT.2007.902277

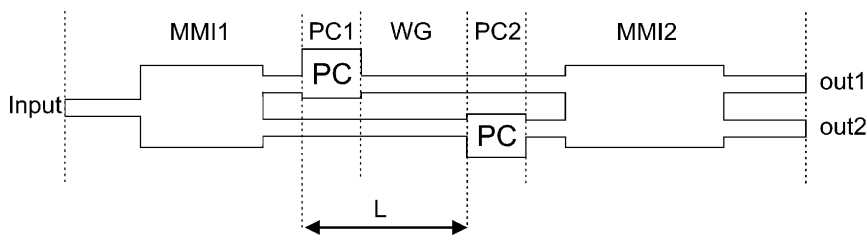

Fig. 1. Schematic of the MZI polarization splitter/converter.

the input waveguide of the first multimode interference (MMI) coupler is split into the two branches with equal power and phase. In the upper branch, a PC is placed that rotates the polarization $90^{\circ}$, so after this, the orthogonal polarization propagates through this branch.

In the lower branch, the light in the original polarization propagates over a distance $L$ before being rotated in a PC. The birefringence in the waveguides causes a phase shift between light in the arms. This phase shift is equal in magnitude but opposite in sign for both polarizations. When both signals are combined in the output MMI, the phase difference causes one polarization to appear in one of the outputs while the opposite polarization goes to the other output. To achieve the desired splitting, the phase difference between the branches needs to be $\pm(\pi / 2)$ radians. This is obtained when $L=\pi /\left(2\left(\beta_{\mathrm{TE}}-\beta_{\mathrm{TM}}\right)\right)$, where $\beta_{\mathrm{TE}, \mathrm{TM}}$ are the propagation constants for the two (transverse electric or transverse magnetic) polarizations.

The PC consists of a ridge waveguide with a straight and a slanted wall [9], [10].

\section{ANALYSIS}

The polarization splitter circuit is simulated by concatenating the transfer matrices of each of the sections in the device (Fig. 1): the input coupler (MMI1); a PC in the upper arm (PC1); straight waveguides of length $L$ in both branches (WG); a PC in the lower arm (PC2); and the output coupler (MMI2). Simulation results as a function of the conversion $\left(c_{\mathrm{PC}}=\left(P_{\mathrm{TM}}\right) /\left(P_{\mathrm{TE}}+P_{\mathrm{TM}}\right)\right)$ of the PCs in the arms, with TE polarized light at the input, are shown in Fig. 2(a). The power of TE polarized light from the outputs is only zero if the conversion in the arms $c_{\mathrm{PC}}=1$. For a lower conversion, the nonconverted part is split equally over the two branches. The conversion of the PCs depends critically on the width $( \pm 50 \mathrm{~nm}$ needed for $c_{\mathrm{PC}}>90 \%$ [9]), so these devices are considered to be the limiting factor in the performance. The influence of the coupling coefficient of the couplers is less important as MMIs can be made tolerant to width deviations [11].

With these, Fig. 3 shows the splitting ratio of the splitter for a coupling coefficient of 0.5 for MMI2, defined as

$$
\mathrm{SR}\left(\mathrm{TE}_{\mathrm{in}}\right)=10 \log \left(\frac{P_{\mathrm{TM}_{\text {out } 1}}+P_{\mathrm{TE}_{\text {out } 1}}}{P_{\mathrm{TM}_{\text {out } 2}}+P_{\mathrm{TE}_{\text {out } 2}}}\right) .
$$






(a)

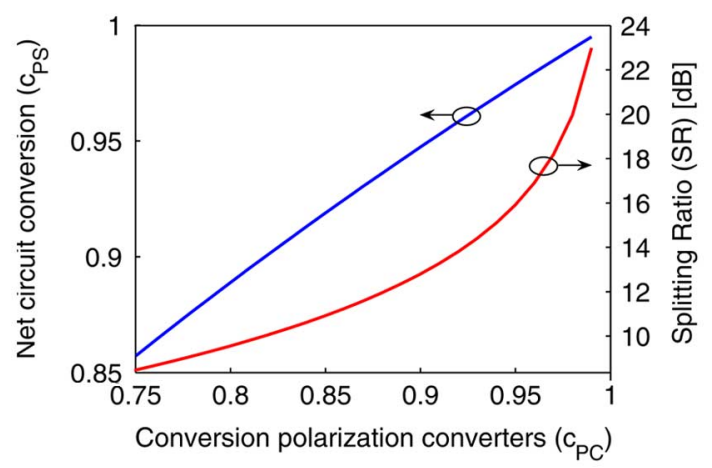

(b)

Fig. 2. Simulated performance of the integrated polarization splitter/converter as a function of the polarization conversion of the converters in the branches for TE input. (a) Output from output Ports 1 and $2\left(\mathrm{TM}_{\mathrm{out} 2}\left(\mathrm{TE}_{\mathrm{in}}\right)\right.$ is always zero in this $\left(L=\pi /\left(2\left(\beta_{\mathrm{TE}}-\beta_{\mathrm{TM}}\right)\right)\right)$ case $)$. (b) Resulting conversion and splitting ratio.

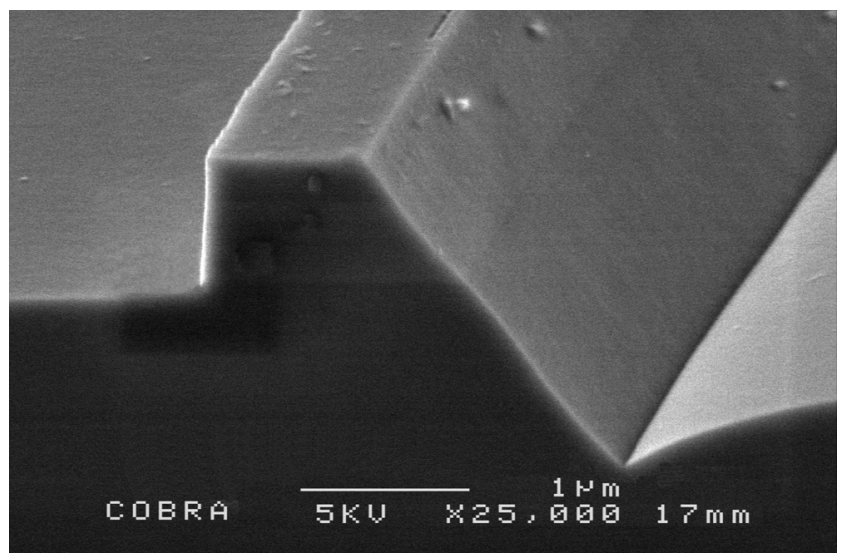

Fig. 3. Scanning electron microscope photograph of a realized PC.

For a splitting ratio larger than $13 \mathrm{~dB}$, a conversion $c_{\mathrm{PC}}$ above $90 \%$ is needed. The total conversion of the splitter circuit $c_{\mathrm{PS}}$ at the wanted output port is larger than $95 \%$, because the unconverted part is split equally over the outputs.

\section{FABRICATION}

The waveguides used in the splitter are $2 \mu \mathrm{m}$ wide, and deeply etched into a layer stack having a 300-nm InP top cladding, and a 500-nm $Q(1.25)$ waveguide layer on an InP substrate. This yields a $\Delta \beta=\beta_{\mathrm{TE}}-\beta_{\mathrm{TM}}$ of $0.03 \mu \mathrm{m}^{-1}$, so for this device an offset $L$ between the converters of $52 \mu \mathrm{m}$ is needed. The total length of the device, including input and output MMIs, is

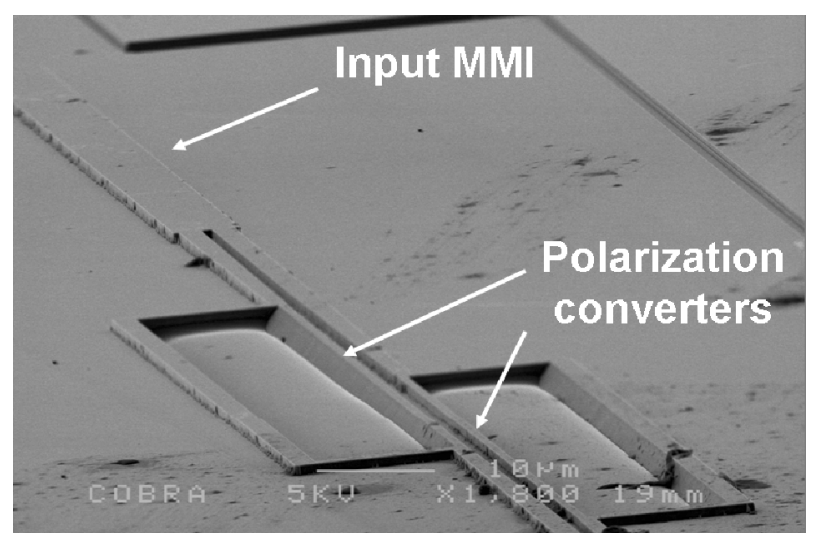

Fig. 4. Photograph of the input MMI and two PCs in the arms of the MZI.

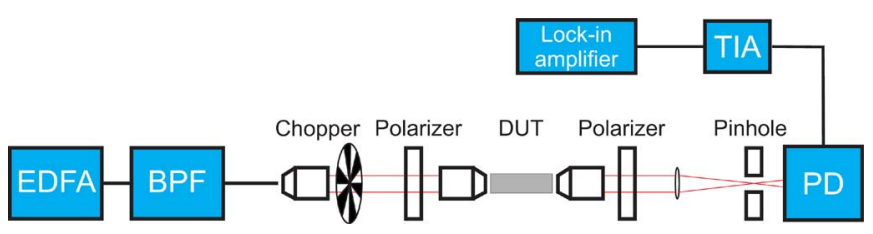

Fig. 5. Setup used for characterization of the polarization splitter and converter. BPF: Bandpass filter. PD: Photodiode. TIA: Transimpedance amplifier.

about $600 \mu \mathrm{m}$. The device is coupled to $1.8-\mathrm{mm}$-long shallow waveguides (etched $100 \mathrm{~nm}$ into the waveguide layer). The PCs consist of an asymmetric waveguide with a straight and a slanted sidewall.

On one chip, separate PCs and the integrated splitter/converter are fabricated (Figs. 3 and 4). The processing of the polarization splitter/converter is similar to the process described earlier [9]. All waveguides are defined by lift-off of Ti on top of silicon nitride. The lithographical definition is made in an ASML PAS5500/250 $5 \times$ reduction wafer stepper. This allows a very accurate width control, better than $20 \mathrm{~nm}$ on an 800-nm line. This optical lithography is advantageous as compared to electron beam lithography, because it has a large writing field, better uniformity, and is suited for mass production.

The etching of the waveguides and the straight side of the PC is done in a $\mathrm{CH}_{4}-\mathrm{H}_{2}$ reactive ion etching. The slanted side is etched in $\mathrm{a} \mathrm{Br}_{2}-$ methanol solution. This etchant etches both InP and InGaAsP anisotropically with an angle of $54^{\circ}$ with respect to the surface, as shown in Fig. 3.

\section{Characterization}

Both the integrated splitter/converter and the separate PCs on the same chip are examined with the setup shown in Fig. 5. The devices are exited using an erbium-doped fiber amplifier as a source and a 2.5-nm-wide bandpass filter, set to a central wavelength of $1555 \mathrm{~nm}$. This signal is chopped and the polarization is fixed using a polarizer. The light is coupled into the chip and the output is coupled through a polarizer to determine the output polarization. It is detected with a photodiode connected to a transimpedance amplifier and a lock-in amplifier. The separate PCs are measured first. The conversion as a function of the width of the device is examined. The results are shown in Fig. 6.

A conversion of $95 \%$ can be achieved for a width of $0.75 \mu \mathrm{m}$. The PCs used in the splitter are $0.8 \mu \mathrm{m}$ wide, as the simulated maximum conversion of $99 \%$ would be for this width. Due to 


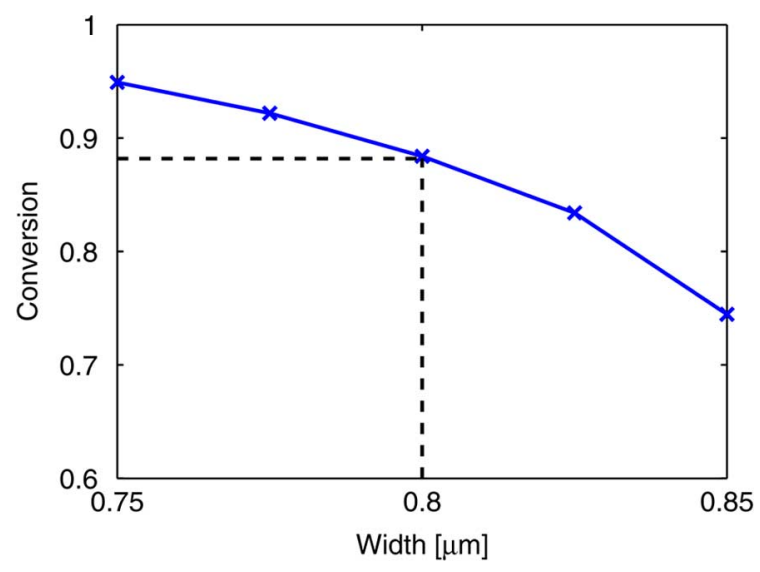

Fig. 6. Measured conversion as a function of width of PC (the dashed line shows the converter used in the integrated splitter).

TABLE I

Measured Output Powers and Resulting Splitting Ratio AND CONVERSION

\begin{tabular}{l||l|l}
\hline & $\mathrm{P}_{\text {out }}\left(\mathrm{TE}_{\text {in }}\right)$ [a.u.] & $\mathrm{P}_{\text {out }}\left(\mathrm{TM}_{\text {in }}\right)$ [a.u.] \\
\hline \hline $\mathrm{TE}_{\text {out 1 }}$ & 4.5 & 1.3 \\
$\mathrm{TE}_{\text {out2 }}$ & 2.6 & 47.3 \\
$\mathrm{TM}_{\text {out } 1}$ & 43.7 & 2.5 \\
$\mathrm{TM}_{\text {out2 }}$ & 3.4 & 4.9 \\
\hline conversion $c_{P S}$ & $91 \%$ & $91 \%$ \\
$\mathrm{SR}$ & $9.1 \mathrm{~dB}$ & $11.4 \mathrm{~dB}$ \\
\hline
\end{tabular}

inaccuracies in the model, the actual maximum conversion occurs at a different width. According to the measurements, the converter used in the splitter will have a conversion of $88 \%$. A higher conversion is expected for narrower waveguides. The full splitter/converter is measured at the same wavelength. The results are stated in Table I.

The conversion $c_{\mathrm{PC}}$ of the converters in the branches for $\mathrm{TE}$ (for TM) can be calculated by dividing the output power in TM (TE) in both outputs by the total power from both outputs

$$
c_{\mathrm{PC}}\left(\mathrm{TE}_{\mathrm{in}}\right)=\frac{P_{\mathrm{TM}_{\mathrm{out} 1}}+P_{\mathrm{TM}_{\mathrm{out} 2}}}{P_{\mathrm{TE}_{\mathrm{out} 1}}+P_{\mathrm{TE}_{\mathrm{out} 2}}+P_{\mathrm{TM}_{\mathrm{out} 1}}+P_{\mathrm{TM}_{\mathrm{out} 2}}} .
$$

The conversion equals $87 \%$. The net conversion of the device $c_{\mathrm{PS}}$ is $91 \%$ for both polarizations. This is less than the expected net conversion from Fig. 2(b). This is probably caused by an imperfect output coupler.

The resulting splitting ratio, defined in (1), is $9.1 \mathrm{~dB}$ for $\mathrm{TE}_{\text {in }}$ and $11.4 \mathrm{~dB}$ for $\mathrm{TM}_{\mathrm{in}}$. The low splitting ratio is caused by a deviation from the actual $L$ to the optimal $L=\pi /\left(2\left(\beta_{\mathrm{TE}}-\right.\right.$ $\left.\beta_{\mathrm{TM}}\right)$ ), caused by imperfections in the model to calculate the propagation constants of the modes.

The difference in splitting ratio for TE and TM is caused by the polarization dependence of the output coupler. The input coupler is a $1 \times 2$ coupler and its splitting is symmetric, inherent to the design and thus polarization-independent.

The excess losses are $5.0 \pm 0.1 \mathrm{~dB}$ compared to a straight $3-\mu \mathrm{m}$ shallow waveguide. The PCs have a loss of $1.5 \pm 0.3 \mathrm{~dB}$; both the input and output MMI have an expected loss of $1 \mathrm{~dB}$.
The additional losses are most probably caused by the waveguide roughness which is visible in Fig. 4. The narrow, deeply etched waveguides in the splitter suffer more from the roughness than the shallow connecting waveguides. The roughness is mainly caused by a nonoptimal lift-off process used for the masking of the waveguides. Improved fabrication and adjustments to the design will lead to lower losses and better performance.

\section{CONCLUSION}

A novel type of interference-based integrated polarization splitter and converter is presented. The device is simulated using the transfer matrix method. Splitting ratios larger than $95 \%$ are expected for conversion ratios of the converters of more than $90 \%$. The PCs are the limiting factor in the fabrication process. The device is fabricated and measurements show a splitting of $9.1 \mathrm{~dB}$ for TE, $11.4 \mathrm{~dB}$ for TM, and a conversion of $91 \%$. This device has the potential to be a short splitter that can be integrated with active and passive components, easier than a shorter photonic-crystal-based splitter.

\section{ACKNOWLEDGMENT}

The authors would like to thank the Centre for Integrated Photonics, Ipswich, U.K., for supplying the wafer for this experiment.

\section{REFERENCES}

[1] R. Hanfoug, J. J. G. M. van der Tol, L. M. Augustin, and M. K. Smit, "Wavelength conversion with polarisation labelling for rejection and isolation of signals (POLARIS)," in Proc. 11th Eur. Conf. Int. Opt. (ECIO'03), Prague, Czech Republic, Apr. 2-4, 2003, pp. 105-108.

[2] P. Albrecht, M. Hamacher, H. Heidrich, D. Hoffmann, H.-P. Nolting, and C. M. Weinert, "TE/TM mode splitters on InGaAsP/InP," IEEE Photon. Technol. Lett., vol. 2, no. 2, pp. 114-115, Feb. 1990.

[3] M. R. Watts and H. A. Haus, "Integrated mode-evolution-based polarization rotators," Opt. Lett., vol. 30, pp. 138-140, Jan. 2005.

[4] J. J. G. M. van der Tol, J. W. Pedersen, E. G. Metaal, Y. S. Oei, H. van Brug, and I. Moerman, "Mode evolution type polarization splitter on InGaAsP/InP," IEEE Photon. Technol. Lett., vol. 5, no. 12, pp. 1412-1414, Dec. 1993.

[5] J. J. G. M. van der Tol, J. W. Pedersen, E. G. Metaal, J.-W. van Gaalen, Y. S. Oei, and F. H. Groen, "A short polarization splitter without metal overlays on InGaAsP-InP," IEEE Photon. Technol. Lett., vol. 9, no. 2, pp. 209-211, Feb. 1997.

[6] L. M. Augustin, J. J. G. M. van der Tol, R. Hanfoug, W. J. M. de Laat, M. J. E. van de Moosdijk, P. W. L. van Dijk, Y. S. Oei, and M. K. Smit, "A single etch-step fabrication-tolerant polarization splitter," $J$. Lightw. Technol., vol. 25, no. 3, pp. 740-746, Mar. 2007.

[7] V. Zabelin, L. Dunbar, N. L. Thomas, R. Houdré, M. Kotlyar, L. O'Faolain, and T. F. Krauss, "Self-collimating photonic crystal polarization beam splitter," Opt. Lett., vol. 32, pp. 530-532, Mar. 2007.

[8] L. M. Augustin, J. J. G. M. van der Tol, R. Hanfoug, W. de Laat, and M. K. Smit, "An integrated polarization splitter/converter on InP/ InGaAsP," in Proc. Int. Symp. Contemporary Photonics Technology, Tokyo, Japan, Jan. 2007, pp. 101-102.

[9] U. Khalique, Y. Zhu, J. J. G. M. van der Tol, L. M. Augustin, R. Hanfoug, F. H. Groen, P. van Veldhoven, M. K. Smit, M. van de Moosdijk, W. de Laat, and K. Simon, "Ultrashort polarization converter on InP/InGaAsP fabricated by optical lithography," in Tech. Dig. Integr. Photon. Res. Apps. (IPRA'05), San Diego, CA, Apr. 11-13, 2005, Paper IWA3.

[10] H. El-Refaei, D. Yevick, and T. Jones, "Slanted-rib waveguide InGaAsP-InP polarization converters," J. Lightw. Technol., vol. 22, no. 5, pp. 1352-1357, May 2004.

[11] M. T. Hill, X. J. M. Leijtens, G. D. Khoe, and M. K. Smit, "Optimizing imbalance and loss in $2 \times 23$-dB multimode interference couplers via access waveguide width," J. Lightw. Technol., vol. 21, no. 10, pp. 2305-2313, Oct. 2003. 